\title{
Global Peginterferon Beta-1a Tolerability Management Best Practices: A Nurse-Focused Delphi Approach
}

\author{
Sarah White Colleen Harris · Michelle Allan · Carol Chieffe · \\ Piet Eelen · Claudia Röder · Catherine Mouzawak · Maria L. Naylor
}

Received: December 14, 2020 / Accepted: February 25, 2021 / Published online: March 24, 2021

(C) The Author(s) 2021

\section{ABSTRACT}

Introduction: Injection site reactions (ISRs) and flu-like symptoms (FLS) are common in patients with relapsing forms of multiple sclerosis (MS) treated with peginterferon beta-1a. The purpose of this Delphi analysis was to explore peginterferon beta-1a discontinuation rates across MS

Sarah White and Colleen Harris are co-first authors.

S. White

St George's University Hospitals, London, UK

C. Harris

Foothills Medical Centre, Calgary, AB, Canada

M. Allan

Monash Health, Clayton, VIC, Australia

C. Chieffe

Allegheny Neuroscience Institute, Monroeville, PA, USA

P. Eelen

Nationaal Multiple Sclerose Centrum V.Z.W., Melsbroek, Belgium

C. Röder

Drs A. Stockert/C. Rettenmayr, Pforzheim, Germany

C. Mouzawak

Réseau SEP IDF Ouest, Saint-Germain-en-Laye, France

M. L. Naylor $(\bowtie)$

Biogen, Cambridge, MA, USA

e-mail: maria.naylor@biogen.com treatment centers, to obtain consensus on effective mitigation and management strategies for ISRs and FLS, and to identify areas where additional training and education for nurses and patients could improve treatment outcomes.

Methods: In this modified Delphi process, an international steering committee of eight MS-certified nurses developed two rounds of surveys, which were completed by 262 and 188 MS nurses, respectively, representing nine countries.

Results: On average, nurses reported that 25\% and $30 \%$ of patients treated with peginterferon beta-1a experienced ISRs and FLS, respectively. Discontinuation due to severe ISRs or FLS was most common in the first 6 months of treatment, yet follow-up visits typically took place 6 months after peginterferon beta-1a initiation. Preferred management strategies for ISRs included nonsteroidal anti-inflammatory drugs and rotation of the injection site, whereas preferred management strategies for FLS included acetaminophen/paracetamol and hydration/ nutrition. Most nurses (77\%) agreed that additional education and training on ISR and FLS management would bolster their confidence in treating patients with these symptoms.

Conclusion: Delphi respondents reached consensus on ISR and FLS management strategies, which can help to inform treatment decisions. The results of this global Delphi analysis indicate that management of ISRs and FLS could be 
improved with more frequent follow-up visits and individualized training and education.

Keywords: Delphi; Flu-like symptoms; Injection site reaction; Peginterferon beta-1a; Tolerability

\section{Key Summary Points}

\section{Why carry out this study?}

Injection site reactions (ISRs) and flu-like symptoms (FLS) are common adverse events associated with peginterferon beta$1 \mathrm{a}$ treatment in patients with relapsing forms of multiple sclerosis (MS) and can lead to treatment discontinuation.

The purpose of this global Delphi analysis was to explore peginterferon beta- 1 a discontinuation rates across MS treatment centers, to obtain consensus on effective mitigation and management strategies for ISRs and FLS, and to identify areas where additional training and education for nurses and patients could improve treatment outcomes.

\section{What was learned from the study?}

Preferred management strategies for ISRs included nonsteroidal anti-inflammatory drugs and rotation of the injection site, whereas preferred management strategies for FLS included acetaminophen/ paracetamol and hydration/nutrition.

The results of this analysis indicate a need among MS nurses for additional training and education on ISR and FLS management.

Individualized patient treatment and education, as well as more frequent follow-up visits, may help to improve adherence and persistence to peginterferon beta-1a.

\section{DIGITAL FEATURES}

This article is published with digital features, including a summary slide, to facilitate understanding of the article. To view digital features for this article go to https://doi.org/10.6084/ m9.figshare.14102738.

\section{INTRODUCTION}

Subcutaneous (SC) peginterferon beta-1a every 2 weeks is approved in the United States and Australia to treat relapsing forms of multiple sclerosis (MS) and is approved in the European Union to treat relapsing-remitting MS. The safety and efficacy of peginterferon beta-1a were established based on results from the phase 3 ADVANCE study $[1,2]$ and its extension study, ATTAIN [3]. As of September 30, 2019, approximately 54,895 patients have been prescribed subcutaneous (SC) peginterferon beta-1a, representing approximately 99,218 patient-years of exposure [4].

Common adverse events (AEs) associated with peginterferon beta-1a treatment include injection site reactions (ISRs) and flu-like symptoms (FLS). In the ADVANCE study, ISRs and FLS were reported in $68 \%$ and $79 \%$, respectively, of patients treated with peginterferon beta-1a every 2 weeks [1-3]. In ATTAIN, the 2-year extension study of ADVANCE, ISRs and FLS were also the most common AEs; they were reported in $43 \%$ and $62 \%$, respectively, of patients treated with peginterferon beta-1a every 2 weeks [3]. In the third interim data cut of the real-world phase 4 Plegridy Observational Program (POP), ISRs and FLS were reported in $38 \%$ and $41 \%$ of patients, respectively [5].

Disease-modifying therapies (DMTs) are long-term therapies for MS; thus, adherence is essential to optimize treatment outcomes. Adherence to DMTs has been associated with improved clinical outcomes in patients with MS, including lower risk of MS relapse and higher quality of life $[6,7]$. Results from the real-world PRIME study indicated that over 2 years of peginterferon beta-1a treatment, the percentage of patients with an adherence rate $>90 \%$ was $75.7 \%$ (95\% confidence interval 
67.9-81.6), and the adherence rate remained stable over this period [8].

Persistence, likewise, is important to optimize treatment outcomes. In ADVANCE, $6 \%$ of patients receiving peginterferon beta- $1 \mathrm{a}$ every 2 weeks discontinued due to an $\mathrm{AE}$ over the course of 2 years [2]. In the ATTAIN extension study, $5 \%$ of patients receiving peginterferon beta-1a every 2 weeks discontinued due to an AE during years 3-6 [3]. In ADVANCE, the most common AE leading to treatment discontinuation was influenza-like illness, which led to discontinuation in $<1 \%$ of patients receiving peginterferon beta-1a every 2 weeks [1]. Similarly, in ATTAIN, no AE leading to study discontinuation had an incidence $\geq 1 \%$; the most common AEs leading to study discontinuation included MS relapse $(n=5)$, hepatic toxicity $(n=3)$, influenza-like illness $(n=3)$, and alanine aminotransferase increase $(n=3)$ [3].

While rates of discontinuation due to ISRs or FLS were relatively low in both ADVANCE and ATTAIN, discontinuation rates have been higher in real-world clinical settings. Results from the third interim analysis of the real-world POP study demonstrated that discontinuation of peginterferon beta- $1 \mathrm{a}$ on account of $\geq 1 \mathrm{AE}$ occurred in $18.4 \%$ of patients and that the majority of these discontinuations were due to ISRs (5.2\%) or FLS (10.2\%) [5]. The real-world German patient support program (PSP) assessed discontinuation due to ISRs and FLS in 6276 patients treated with peginterferon beta-1a [9]. Of these patients, $12 \%$ discontinued due to ISRs and 34\% discontinued due to FLS [9]. These initial results from real-world studies highlight the need for more effective mitigation strategies in patients treated with peginterferon beta- 1 a.

Previous studies have explored the impact of setting realistic treatment expectations and providing patient education, in addition to following best practices for ISR and FLS mitigation and management, on adherence and persistence to peginterferon beta-1a treatment. In a Delphi analysis based on responses from ADVANCE investigators, responders agreed that patient education on ISRs and FLS prior to initiation of treatment was critical to ensure high adherence and low treatment discontinuation [10]. Injection site rotation, cooling of the injection site, and drug administration at room temperature were recommended for the management of ISRs, whereas acetaminophen/ paracetamol, NSAIDs, and altered injection timing were recommended for managing FLS [10]. A second Delphi analysis based on input from principal investigators and study coordinators from the phase $3 \mathrm{~b}$ ALLOW trial identified on-site education by a clinician prior to treatment initiation as the most effective mitigation strategy for ISRs [11]. With respect to post-injection strategies, respondents reached consensus that while injection site rotation was advisable, redness may persist for many patients. Further, respondents agreed that follow-up after the first injection was helpful to ensure that ISRs were not causing more concern than expected for the patient [11]. Results from the real-world German PSP study support the role of patient education, as peginterferon beta1a discontinuations due to ISRs and FLS within the first year were reduced by $43 \%(p<0.0001)$ and $22 \%(p=0.001)$, respectively, in patients who received individualized coaching [9].

This Delphi analysis expands upon previous studies by using global survey data from MS nurses in eight countries to obtain consensus on effective mitigation and management strategies for ISRs and FLS and to identify additional training and education for both nurses and patients that could help to optimize treatment outcomes.

\section{METHODS}

The Delphi technique is a widely used communication process designed to identify group consensus or lack of consensus on a particular issue through iterative rounds of questions. A modified Delphi process was implemented in this study, which consisted of two rounds of anonymous 20-min surveys.

The international steering committee for this Delphi process was composed of eight MScertified nurses. The objectives of the steering committee were to explore the variability of rates of peginterferon beta-1a treatment discontinuation across MS treatment centers, obtain consensus on effective approaches for 
the management of ISRs and FLS, and identify areas in which further training and education for both nurses and patients may help to optimize outcomes for patients receiving peginterferon beta-1a treatment.

The first survey was developed based on the steering committee's identification of key data and knowledge gaps in the mitigation and management of ISRs and FLS in patients treated with peginterferon beta-1a. The survey consisted of 41 questions regarding nurse and patient demographics, discontinuation of peginterferon beta- $1 \mathrm{a}$, characteristics and management of ISRs and FLS, and education and training for nurses and patients. The second survey, which consisted of 34 questions, focused on issues about which the steering committee could not reach a consensus, based on the results of the first survey. Only nurses who had completed the first round of the survey were invited to participate in the second round.

Nurses and nurse practitioners were screened prior to participating in the survey. Respondents were included if they were currently caring for patients with MS, had cared for patients with MS for at least 1 year, had treated more than five patients with peginterferon beta-1a in the past 2 years, and held no nursing responsibilities sponsored by a pharmaceutical company that were related to treating patients with MS.

Survey respondents included MS nurses from nine countries: eight countries in Europe and North America, plus Australia. Respondents provided demographic information and answers to survey questions through a webbased survey tool (provided by Ashfield Insight and Performance). In the first round, surveys were issued until a target number of respondents was reached. The second survey was sent to all nurses who participated in the first survey.

\section{Compliance with Ethics Guidelines}

All survey respondents provided electronic informed consent prior to participation and had the right to refuse to answer any question or to withdraw from the study at any time. The survey screened out any respondents with nursing responsibilities related to treating MS patients that were sponsored by a pharmaceutical company. Respondents were aware of the study objectives and were informed that the results of the survey would be used for research purposes. The data were anonymized to protect respondents' identities. No ethics committee was required, as no patients were involved in this study, and no identifying information is included in this manuscript. This study was performed in accordance with the Helsinki Declaration of 1964.

\section{RESULTS}

\section{Demographics: Nurses and Clinical Practices}

The two rounds of the survey were completed approximately 4 months apart by 262 and 188 nurses, respectively; $72 \%$ of nurses who completed the first survey also completed the second survey. In both rounds of the survey, the United States was the country with the most respondents ( $n=66$ and 46, respectively), while Europe was the continent with the most respondents ( $n=177$ and 127, respectively; Table 1).

On average, nurses reported that 158 patients with MS per year were treated at their clinical practices (Table 1 ). In the last 2 years, $47 \%$ of nurses had treated $6-10$ patients, $31 \%$ had treated $11-20$ patients, and $23 \%$ had treated more than 20 patients with peginterferon beta-1a.

Of the nurses surveyed, $63 \%$ were responsible for managing peginterferon beta-1a-related side effects, while $47 \%$ were involved in treatment decisions. Most respondents (84\%) reported that they and other MS nurses had primary responsibility for managing ISRs and FLS in patients treated with peginterferon beta$1 \mathrm{a}$. The majority of nurses (83\%) reported collecting information on patients' quality of life and activities of daily living. This information was collected through formal and informal methods and encompassed family life, work, mobility, social life, self-care, cognition, and other characteristics such as sexual/urinary function and home layout. 
Table 1 Characteristics of survey respondents by country

\begin{tabular}{|c|c|c|c|c|c|c|c|c|c|c|}
\hline \multirow{2}{*}{$\begin{array}{l}\text { Respondent } \\
\text { characteristic }\end{array}$} & \multirow[t]{2}{*}{ Total } & \multicolumn{9}{|c|}{ Country } \\
\hline & & USA & Germany & Spain & France & Italy & UK & Australia & Canada & Belgium \\
\hline $\begin{array}{l}\text { Round } 1 \\
\quad \text { respondents, } n\end{array}$ & 262 & 66 & 36 & 35 & 34 & 34 & 34 & 10 & 9 & 4 \\
\hline $\begin{array}{l}\text { Round } 2 \\
\quad \text { respondents, } n\end{array}$ & 188 & 46 & 24 & 26 & 21 & 25 & 28 & 7 & 8 & 3 \\
\hline \multicolumn{11}{|c|}{ No. of years caring for patients with MS, $n(\%)^{\mathrm{a}}$} \\
\hline $1-5$ years & $68(26)$ & $15(23)$ & $15(42)$ & $6(17)$ & $12(35)$ & $10(29)$ & $5(15)$ & $2(20)$ & $2(22)$ & $1(25)$ \\
\hline$>5$ years & $\begin{array}{l}194 \\
(74)\end{array}$ & $51(77)$ & $21(58)$ & $29(83)$ & $22(65)$ & $24(71)$ & $29(85)$ & $8(80)$ & $7(78)$ & $3(75)$ \\
\hline $\begin{array}{l}\text { No. of MS } \\
\text { patients treated } \\
\text { at respondents' } \\
\text { clinical } \\
\text { practices/year, } \\
\text { mean }(\mathrm{SD})^{\mathrm{a}}\end{array}$ & $\begin{array}{l}158 \\
(314)\end{array}$ & $\begin{array}{l}121 \\
(191)\end{array}$ & $\begin{array}{l}130 \\
(296)\end{array}$ & $\begin{array}{l}90 \\
\quad(173)\end{array}$ & $\begin{array}{l}242 \\
\quad(469)\end{array}$ & $\begin{array}{l}162 \\
(319)\end{array}$ & $\begin{array}{l}176 \\
(355)\end{array}$ & $\begin{array}{l}138 \\
(274)\end{array}$ & $\begin{array}{l}245 \\
\quad(553)\end{array}$ & $\begin{array}{l}563 \\
\quad(214)\end{array}$ \\
\hline $\begin{array}{l}\text { No. of patients } \\
\text { treated with } \\
\text { peginterferon } \\
\text { beta- } 1 \text { a cared } \\
\text { for by } \\
\text { respondents in } \\
\text { the past } 2 \text { years, } \\
\text { mean }(S D)^{b}\end{array}$ & $\begin{array}{l}73 \\
\quad(137)\end{array}$ & $\begin{array}{l}69 \\
(132)\end{array}$ & $\begin{array}{l}54.5 \\
\quad(100)\end{array}$ & $64(99)$ & $54(68)$ & $\begin{array}{l}144 \\
\quad(239)\end{array}$ & $\begin{array}{l}72 \\
\quad(125)\end{array}$ & $41(34)$ & $\begin{array}{l}70 \\
(162)\end{array}$ & $10(0)$ \\
\hline
\end{tabular}

$M S$ multiple sclerosis, $S D$ standard deviation

a Survey round 1 data $(n=262)$

b Survey round 2 data $(n=188)$

\section{Discontinuation and Treatment Switching}

On average, nurses reported that $20 \%$ of patients permanently discontinued peginterferon beta-1a. In the first survey round, $47 \%$ of nurses reported FLS as the main reason for discontinuation, whereas $26 \%$ reported lack of efficacy, 22\% reported ISRs, and 5\% reported another factor (including inability to pay, the desire to try something different, and hematological alterations) (Fig. 1).

Averaging across nurses' responses, $64 \%$ of patients treated with peginterferon beta- 1 a were treatment-naive, whereas $36 \%$ of patients had switched from another DMT. Mean overall discontinuation rates were similar in patients who switched from an injectable DMT to peginterferon beta-1a (20\%) and treatment-naive patients $(21 \%)$. Among patients who switched to peginterferon beta-1a from an injectable DMT, the main reason for discontinuation was lack of efficacy (43\%), followed by FLS (33\%), ISRs (21\%), and other reasons (3\%) (Fig. 1). Similarly, among patients who were treatmentnaive, the main reason for discontinuation was lack of efficacy (44\%), followed by FLS (27\%), 

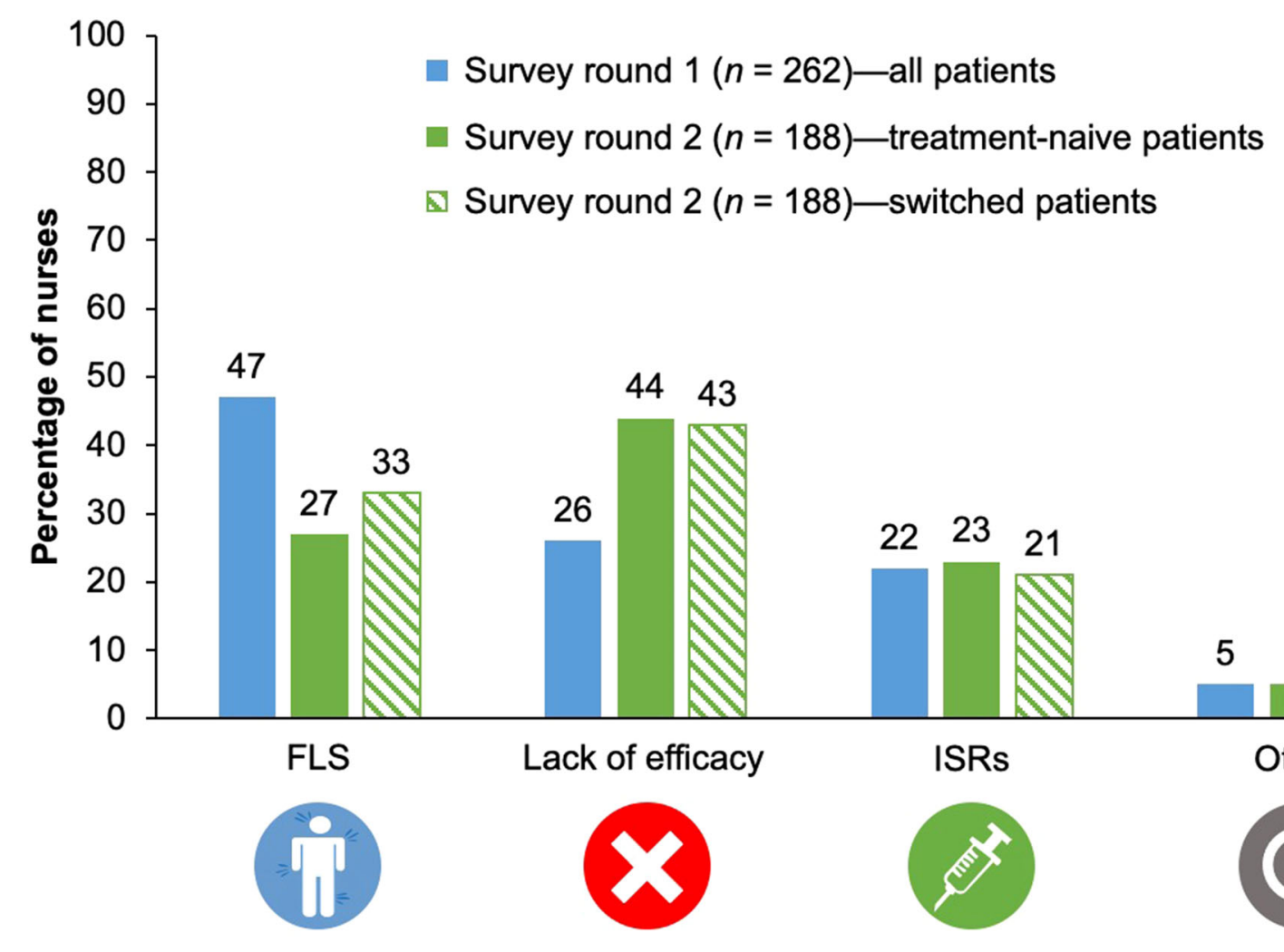

Fig. 1 The primary reason provided by nurses for discontinuation in all patients (survey round $1 ; n=262$ ) and patients who switched from an injectable DMT to peginterferon beta-1a and treatment-naive patients (survey

ISRs (23\%), and other reasons (5\%) (Fig. 1). In contrast to the first round of the survey, in which FLS were reported as the primary reason for discontinuation, lack of efficacy was given as the primary reason for discontinuation in the second round.

\section{ISRs}

On average, nurses reported that $25 \%$ of patients experienced ISRs with peginterferon beta-1a. Among the nurses surveyed, 73\% reported that the average time to onset of ISRs following a peginterferon beta-1a injection was $0.5-2 \mathrm{~h}$. The majority of nurses (64\%) also reported that the average duration of ISRs was $\leq 2$ days. Nurses most frequently reported that the main ISR symptoms that led to discontinuation were pain and redness/erythema.

round $2 ; n=188)$. DMT disease-modifying therapy, FLS flu-like symptoms, ISR injection site reaction

Averaging across nurses' responses, 11\% of patients treated with peginterferon beta-1a experienced severe ISRs. The majority of nurses (77\%) reported that in patients who experienced severe ISRs, the duration on treatment before peginterferon beta-1a discontinuation was $1-3$ or 3-6 months (Fig. 2). Nurses generally determined the severity of ISRs based on swelling and pain. Slightly more than half of nurses (54\%) had received training on how to distinguish between common and severe ISRs. This training most often involved either an external training course, training from a pharmaceutical company or drug representative, or in-house training from a staff supervisor, physician, or pharmacist.

Nurses reported that the effectiveness of ISR management strategies was most commonly assessed every 6 months. Nonsteroidal antiinflammatory drugs (NSAIDs) were nurses' 


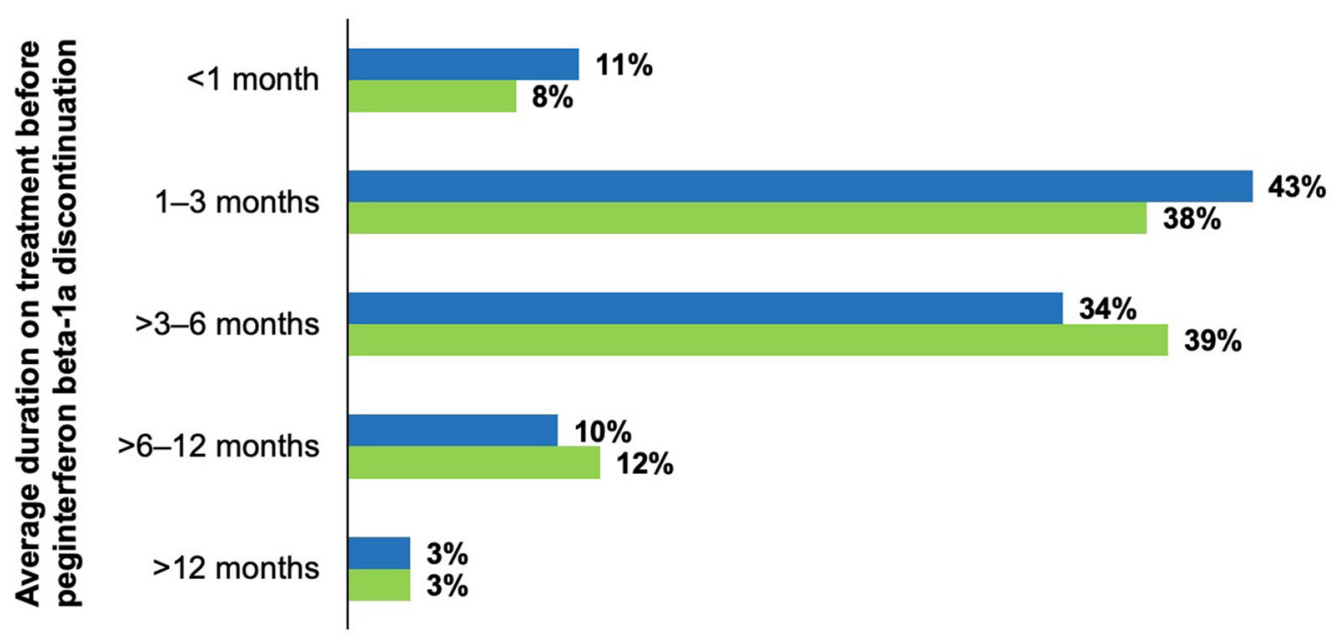

Percentage of nurses $(n=188)$

$\llbracket$ Severe FLS $\because$ Severe ISRs

Fig. 2 Average treatment duration prior to discontinuation in patients with severe ISRs or FLS. Data from survey round 2 $(n=188)$. FLS flu-like symptoms, ISR injection site reaction

preferred (i.e. first-choice) pharmacological strategy for warmth/erythema, pain at the time of injection, and pain $>24 \mathrm{~h}$ after injection, followed by acetaminophen/paracetamol (Fig. 3a). NSAIDs were also the preferred pharmacological strategy for swelling/edema, whereas oral antihistamines were the preferred pharmacological strategy for pruritus (Fig. 3a). Rotation of the injection site was the preferred non-pharmacological strategy for warmth/erythema, pruritus, and swelling/edema (Fig. 3b). Correct injection technique was the preferred non-pharmacological strategy for pain at the time of injection, and application of ice to the injection site was the preferred non-pharmacological strategy for pain $>24 \mathrm{~h}$ after injection (Fig. 3b).

\section{FLS}

On average, nurses reported that $30 \%$ of patients experienced FLS with peginterferon beta-1a. Most nurses (71\%) reported that the onset of FLS was typically within $18 \mathrm{~h}$ of a peginterferon beta-1a injection. Both within the first 3 months of treatment and after 3 months of treatment, nearly half of nurses $(45 \%$ and $46 \%$, respectively) reported that the average duration of FLS was 1-2 days; just over a quarter (27\%) of nurses reported average FLS durations of $<24 \mathrm{~h}$ after 3 months of treatment, compared with approximately one-sixth (16\%) in the first 3 months of treatment.

Nurses most frequently reported that the main FLS that led to discontinuation were body/muscle/joint aches and pain, fever, and fatigue. After 3 months of treatment, most nurses $(75 \%)$ reported that a small minority $(\leq 20 \%)$ of patients with FLS had to change their activities of daily living to continue taking peginterferon beta-1a. In addition, most nurses $(82 \%)$ reported that a small minority $(\leq 20 \%)$ of patients with FLS experienced a negative impact on their quality of life after 3 months of treatment.

On average, nurses reported that $17 \%$ of patients experienced moderate or severe FLS with peginterferon beta-1a. The majority of nurses $(77 \%)$ reported that patients who experienced severe FLS discontinued either 1-3 months or $>3-6$ months after onset of these symptoms (Fig. 2). Moderate-to-severe FLS were usually characterized by muscle/joint pain, fever/chills, and headaches.

Approximately one-third (34\%) of respondents reported a difference in the severity of FLS 
A
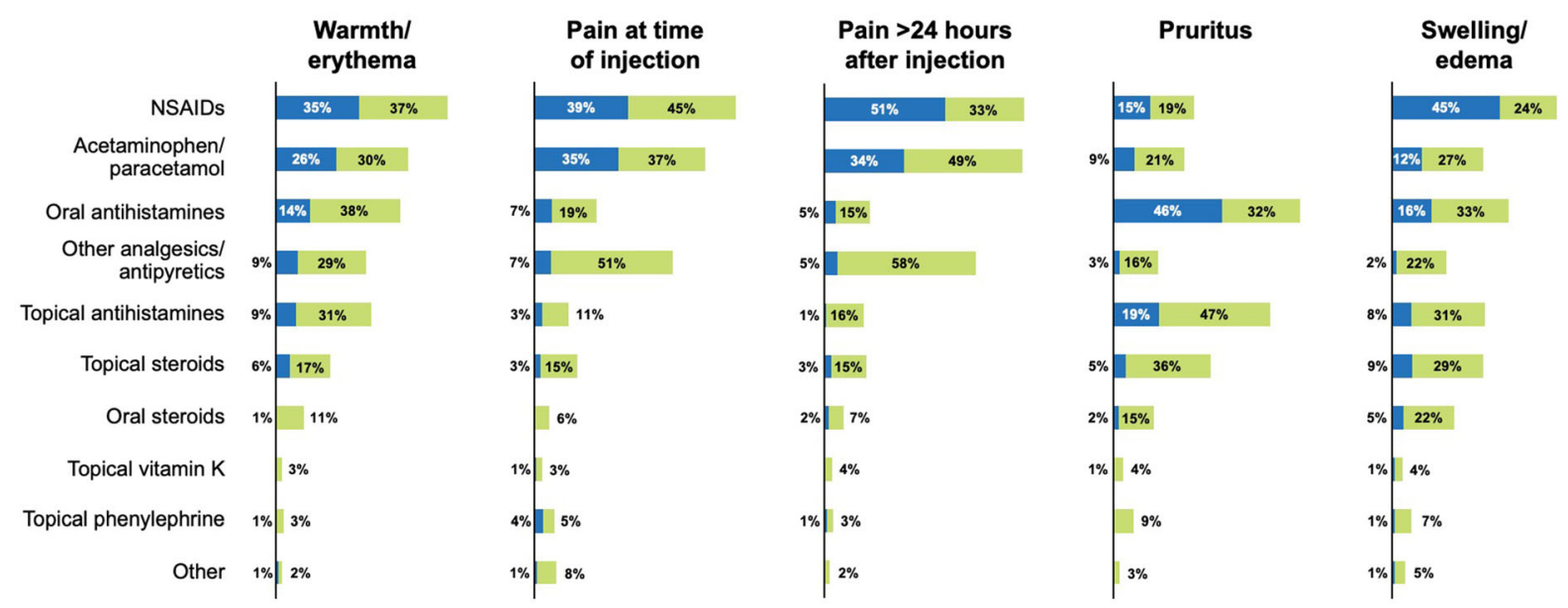

Percentage of nurses $(n=188)$

a First choice Second or third choice

B
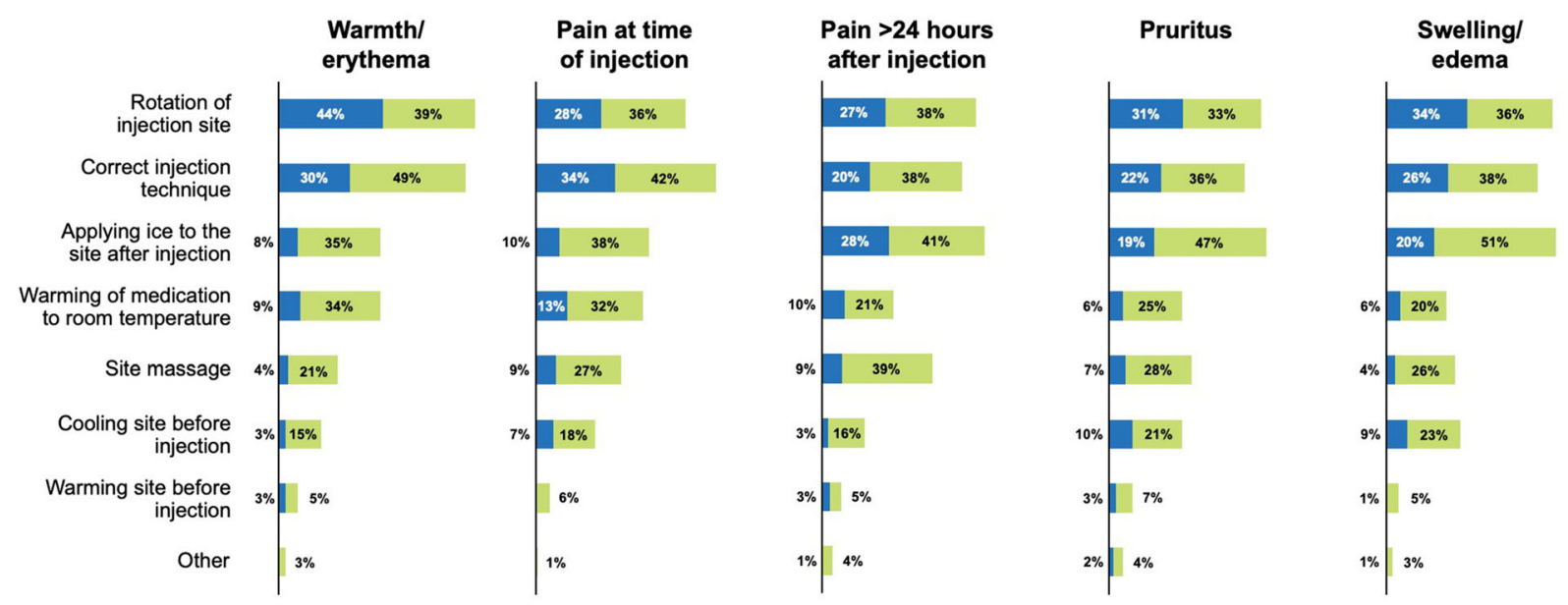

Percentage of nurses $(n=188)$

airst choice $\quad$ Second or third choice

Fig. 3 Percentage of nurses who listed each strategy as their first-, second-, or third-choice strategy for each ISR symptom, among (a) pharmacological and (b) non-pharmacological strategies. The numbers next to each bar indicate the percentage of nurses who selected each strategy

between patients treated with peginterferon beta-1a and those treated with other non-pegylated interferons. Of the nurses who reported such a difference, $38 \%$ said that they managed patients treated with peginterferon beta-1a differently. These differences included (1) paying as a first-choice or second-/third-choice strategy. ISR injection site reaction, NSAID nonsteroidal anti-inflammatory drug

more attention to patients by increasing the number of follow-ups and using stricter patient monitoring, (2) explaining side effects to patients and looking into preventive measures, (3) trying different FLS management techniques, (4) tailoring treatment for each patient, 

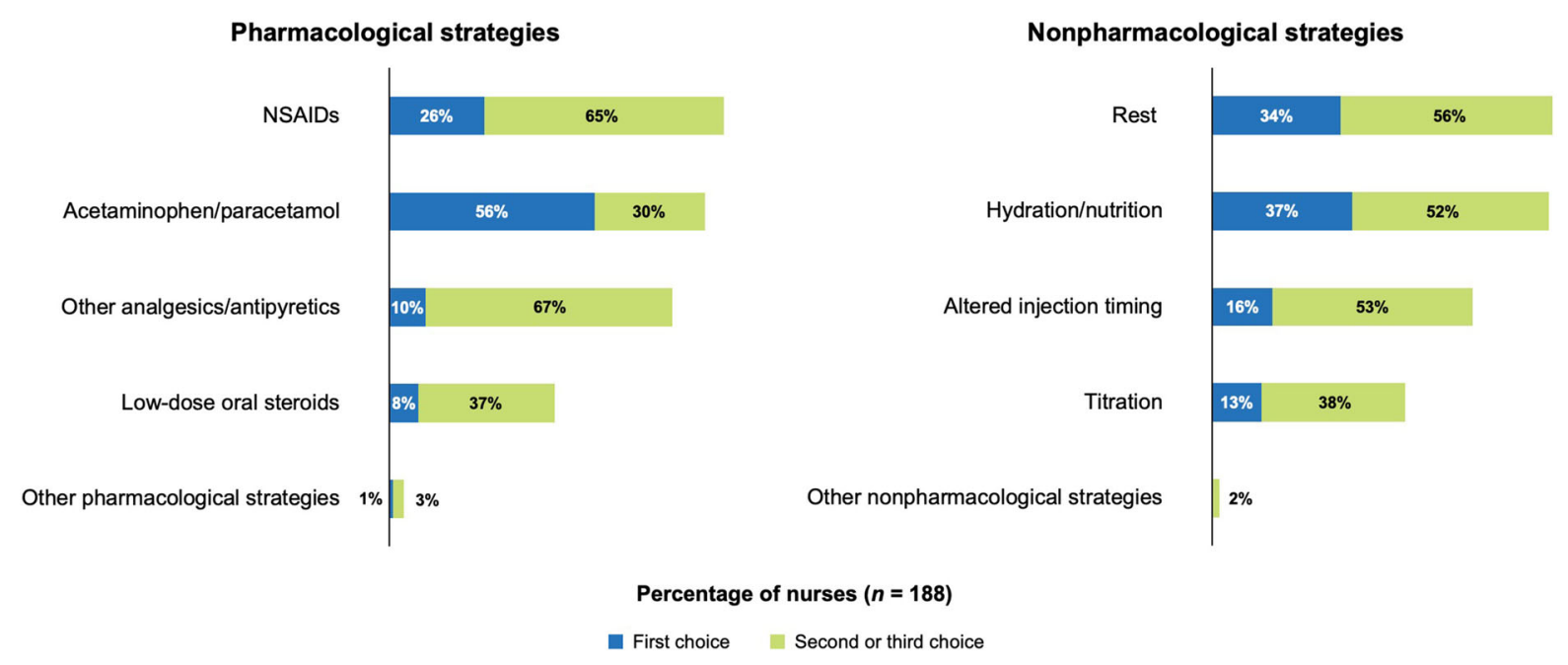

Fig. 4 Percentage of nurses who listed each strategy as their first-, second-, or third-choice strategy for FLS. The numbers next to each bar indicate the total percentage of nurses who selected each strategy as a first-choice or

and (5) working to manage the severity of the symptoms (e.g. with pharmacological/symptomatic and non-pharmacological strategies).

The effectiveness of FLS management strategies was most commonly assessed every 6 months. Nurses' preferred pharmacological strategy for FLS was acetaminophen/paracetamol, followed by NSAIDs (Fig. 4). The preferred non-pharmacological strategy reported for FLS was hydration/nutrition, followed by rest, altered injection timing, and titration (i.e. increasing the dose over time, as indicated in the peginterferon beta-1a prescribing information [12]) (Fig. 4).

\section{Nurse Education/Training}

Of the nurses surveyed, $45 \%$ reported that they had been offered education/training specifically related to peginterferon beta-1a therapy. Of those nurses who were offered education/training, $83 \%$ followed up to receive the training, which was most commonly in house from health care professional staff $(44 \%)$ or company-sponsored (43\%). Of those nurses who were not offered education/training, $42 \%$ indicated that they would like to receive companysponsored training, 36\% would like to receive second-/third-choice strategy. FLS flu-like symptoms, NSAID nonsteroidal anti-inflammatory drug

in-house training from health care professional staff, $21 \%$ would like to receive non-companysponsored training, and $2 \%$ would like to receive another type of training. Most (78\%) of the nurses who would like to receive companysponsored training would prefer in-person training, whereas more than half $(56 \%)$ of the nurses who would like to receive non-companysponsored training would prefer training via a website.

Approximately one-third of nurses (34\%) reported a confidence level of $\leq 6$ (on a scale from 1 to 10 , where $1=$ "not confident" and $10=$ "very confident") in their ability to manage ISRs and FLS associated with peginterferon beta-1a. Most nurses (77\%) agreed that more education/training would increase their confidence in managing ISRs and FLS; 67\% indicated that receiving feedback from or sharing best practices with other health care providers would increase their confidence. Slightly fewer than half of nurses (44\%) would like to receive updates on best practices for managing patients treated with peginterferon beta-1a when relevant updates are available. 


\section{Patient Education/Training}

Most nurses reported that injection training (79\%), FLS management (77\%), and ISR symptom management (74\%) were offered to patients in the first year of treatment. The majority of nurses (76\%) said that they offered the same instruction on management of ISRs and FLS for both treatment-naive patients and those who switched to peginterferon beta-1a from another injectable therapy. Of the $24 \%$ of nurses who did instruct treatment-naive and switched patients differently, just over half reported investing more time in going over treatments and procedures with treatmentnaive patients.

\section{DISCUSSION}

The results of this Delphi survey provide valuable information for MS nurses and clinicians to help improve the treatment and management of peginterferon beta-1a-associated ISRs and FLS. For example, while most nurses reported that follow-up occurred 6 months after initiating treatment, discontinuation due to severe ISRs or FLS most often occurred within the first 6 months, suggesting that those first 6 months are critical for treatment adherence and indicating the need for more frequent follow-up visits during this period. In light of these findings, further research should investigate the association between the frequency of follow-up visits and peginterferon beta-1a discontinuation.

Survey results also provided insight into differences in FLS among interferons. Approximately one-third of nurses reported differences in the severity of FLS in patients treated with peginterferon beta-1a compared with patients treated with non-pegylated interferon. Of those nurses who reported such a difference, 38\% managed patients treated with peginterferon beta-1a differently. It was previously reported that the median FLS duration post injection was $3.2 \mathrm{~h}$ longer with peginterferon beta- $1 \mathrm{a}$ than with non-pegylated interferon beta (17.0 vs. $13.8 \mathrm{~h} ; p<0.001$ ) [13]. However, patients receiving peginterferon beta-1a actually experienced fewer total hours of FLS than those on non-pegylated interferon beta on account of the lower injection frequency of peginterferon beta1a [13]. It is not known how this might affect the perceived severity of FLS associated with peginterferon beta-1a.

Survey results on mitigation strategies to minimize discontinuation were largely consistent with prior studies. Per nurses' reports, approximately $20 \%$ of patients treated with peginterferon beta-1a permanently discontinued treatment, and FLS were most commonly reported as the main reason for discontinuation across all patients. NSAIDs and rotation of the injection site were the preferred strategies to manage most ISR symptoms, whereas acetaminophen/paracetamol and hydration/ nutrition were preferred to manage FLS. The use of rotation of the injection site for ISRs and acetaminophen to treat FLS is in line with previous Delphi studies of mitigation strategies for patients treated with peginterferon beta-1a $[10,11]$. However, reports of discontinuation due to FLS in the current study indicate that improved management strategies are needed. Real-world data from the German PSP study indicated that individualized patient coaching was an effective strategy to reduce rates of discontinuation due to both FLS and ISRs [9]. In the ALLOW study, wide interquartile ranges were reported for the onset $(7.2-15.8 \mathrm{~h})$ and duration (12-22 h) of FLS [13], suggesting that the onset and duration of FLS in each individual patient should be taken into consideration when determining injection timing so that FLS are more likely to occur during sleep. Individualized treatment approaches to injection timing, which was selected as a preferred treatment strategy by nurses in this study, may also help to mitigate FLS.

Whereas FLS were cited as the primary reason for discontinuation in the first round of the survey, lack of efficacy was chosen as the primary reason for discontinuation in the second round. This difference may be related to the different scope of the questions in each survey. For example, in the first survey round, the discontinuation question referred to all patients treated with peginterferon beta- $1 \mathrm{a}$, whereas in the second round, there were two versions of the question, one asking about treatment-naive 
patients and the other about those who switched from an injectable DMT. A second but less likely explanation for this difference is that in the time between the two surveys, lack of efficacy may have supplanted FLS as the most common reason for discontinuation of peginterferon beta-1a on the basis of one or more of the following factors: better patient/nurse education, better treatment of AEs, and/or patients'/nurses' feeling that more efficacious treatments should be used. However, given that there were only 4 months between the surveys, such factors are unlikely to account for the different survey results. Regardless, FLS remain a significant reason for treatment discontinuation, and there is an unmet need for more effective mitigation and management of FLS in order to improve the patient experience.

This study is limited by the use of survey data, which are dependent on the participants' recollection. In addition, not all of the nurses who participated in the first round of the survey participated in the second round, which may have biased the results. Finally, the time between the two surveys may have affected how nurses responded to the survey questions.

\section{CONCLUSIONS}

The results of this modified Delphi analysis indicate a continuing need for training of both nurses and patients. Most nurses surveyed thought that more education and training would increase their confidence. In particular, nurses reported that they would like to receive in-person, company-sponsored training and would also benefit from receiving feedback from or sharing best practices with other health care providers. Survey results also identified a potential need to instruct treatment-naive patients differently from those who were switched from another injectable. These results support the development of additional training and education for nurses to improve their confidence in managing ISRs and FLS and their ability to provide individualized management strategies for patients. While there are many challenges associated with managing ISRs and FLS in patients treated with peginterferon beta- 1a, the results of this Delphi analysis indicate that with individualized and targeted training, education, and mitigation strategies, there is potential to improve patients' experience with peginterferon beta- $1 \mathrm{a}$.

\section{ACKNOWLEDGEMENTS}

The authors thank the Peginterferon Beta-1a Nurse Delphi Steering Committee, Leonor Rubio, DUE, Patrick Harty, PhD, and Christina Caon, MSN, NP-C, for their contributions to the study.

Funding. This study was funded by Biogen. Biogen also funded the Rapid Service Fee for this manuscript.

Medical Writing and Editorial Assistance. The authors were assisted in the preparation of the manuscript by Alexandra D'Agostino, PhD, and Joshua Safran (Ashfield Healthcare Communications, Middletown, CT, USA). Writing and editorial support were funded by the study sponsor.

Authorship. All named authors meet the International Committee of Medical Journal Editors (ICMJE) criteria for authorship for this article, take responsibility for the integrity of the work as a whole, and have given their approval for this version to be published.

Authorship Contributions. All authors contributed to the development of each survey, reviewed the manuscript critically for important intellectual content, and provided final approval of all content.

Disclosures. Sarah White has received fees from Biogen, Celgene, Merck Serono, Novartis, Roche, and Sanofi Genzyme. Colleen Harris has received consulting fees from Biogen, Merck Serono, Novartis, Roche, and Sanofi Genzyme. Michelle Allan has received fees for advisory boards and consulting fees to her institution from Biogen. Carol Chieffe has received fees for speakers' bureaus and advisory boards from Biogen and Sanofi Genzyme. Piet Eelen has 
nothing to disclose. Claudia Röder has received fees for advisory boards and speaker and consulting fees from Biogen, Hollister, Merck, Roche, and Sanofi Genzyme. Catherine Mouzawak has received personal compensation from Biogen, Merck, Novartis, Roche, and Sanofi for advisory board participation and consulting fees. Maria L. Naylor is an employee of Biogen and may hold stock and/or stock options in Biogen.

Compliance with Ethics Guidelines. All survey respondents provided electronic informed consent prior to participation, and they had the right to refuse to answer any question or to withdraw from the study at any time. The survey screened out any respondents with nursing responsibilities related to treating MS patients that were sponsored by a pharmaceutical company. Respondents were aware of the study objectives and were informed that the results of the survey would be used for research purposes. The data were anonymized to protect respondents' identities. No ethics committee was required, as no patients were involved in this study, and no identifying information is included in this manuscript. This study was performed in accordance with the Helsinki Declaration of 1964.

Data Availability. The datasets generated and/or analyzed during the current study are not publicly available. The authors fully support sharing whenever possible. Requests for deidentified data should be made to Biogen via established company data-sharing policies and processes detailed on the website http:// clinicalresearch.biogen.com/.

Open Access. This article is distributed under the terms of the Creative Commons Attribution-NonCommercial 4.0 International License (http://creativecommons.org/licenses/ by-nc/4.0/), which permits any noncommercial use, distribution, and reproduction in any medium, provided the user gives appropriate credit to the original author(s) and the source, provide a link to the Creative Commons license, and indicate if changes were made.
Open Access. This article is licensed under a Creative Commons Attribution-NonCommercial 4.0 International License, which permits any non-commercial use, sharing, adaptation, distribution and reproduction in any medium or format, as long as you give appropriate credit to the original author(s) and the source, provide a link to the Creative Commons licence, and indicate if changes were made. The images or other third party material in this article are included in the article's Creative Commons licence, unless indicated otherwise in a credit line to the material. If material is not included in the article's Creative Commons licence and your intended use is not permitted by statutory regulation or exceeds the permitted use, you will need to obtain permission directly from the copyright holder. To view a copy of this licence, visit http://creativecommons.org/licenses/by$\mathrm{nc} / 4.0 /$.

\section{REFERENCES}

1. Calabresi PA, Kieseier BC, Arnold DL, et al. Pegylated interferon beta-1a for relapsing-remitting multiple sclerosis (ADVANCE): a randomised, phase 3, double-blind study. Lancet Neurol. 2014;13: 657-65.

2. Kieseier BC, Arnold DL, Balcer LJ, et al. Peginterferon beta-1a in multiple sclerosis: 2-year results from ADVANCE. Mult Scler. 2015;21:1025-35.

3. Newsome SD, Scott TF, Arnold DL, et al. Long-term outcomes of peginterferon beta-1a in multiple sclerosis: results from the ADVANCE extension study. ATTAIN Ther Adv Neurol Disord. 2018;11: 1756286418791143 .

4. Zhao Y, Chen K, Ramia N, et al. A phase 1, openlabel crossover study to evaluate the bioequivalence of intramuscular and subcutaneous peginterferon beta-1a in healthy volunteers. Presented at ACTRIMS; February 27-29; West Palm Beach, FL.

5. Salvetti M, Wray S, Popescu C, Everage N, Su R, Naylor M. Safety, pregnancy outcomes, and clinical effectiveness of peginterferon beta-1a for patients with newly diagnosed and non-newly diagnosed relapsing multiple sclerosis: third interim analysis of the Plegridy Observational Program. Presented at ECTRIMS; September 11-13; Stockholm, Sweden. 
6. Tan H, Cai Q, Agarwal S, Stephenson JJ, Kamat S. Impact of adherence to disease-modifying therapies on clinical and economic outcomes among patients with multiple sclerosis. Adv Ther. 2011;28:51-61.

7. Devonshire V, Lapierre Y, Macdonell R, et al. The Global Adherence Project (GAP): a multicenter observational study on adherence to disease-modifying therapies in patients with relapsing-remitting multiple sclerosis. Eur J Neurol. 2011;18:69-77.

8. Menge T, Taipale K, Nastos I, Rehberg-Weber K. Adherence to peginterferon beta-1a in a real-world setting-results from the PRIME (PlegRIdy patient support prograM Evaluation) study. Presented at DGN; November 4-7; Stuttgart, Germany.

9. Niemczyk G, Begus-Nahrmann $Y$, Washeim $\mathrm{N}$, Grundler M-T, Naylor M, Maurer M. Real-world characterisation of peginterferon beta-1a associated flu-like symptoms and injection site reactions and impact of mitigation strategies coached in an individualized patient support program in Germany.
Presented at ECTRIMS; October 10-12; Berlin, Germany.

10. Halper J, Centonze D, Newsome SD, et al. Management strategies for flu-like symptoms and injectionsite reactions associated with peginterferon beta- $1 \mathrm{a}$ : obtaining recommendations using the Delphi technique. Int J MS Care. 2016;18:211-8.

11. Hendin B, Huang D, Wray S, et al. Subcutaneous peginterferon $\beta-1 a$ injection-site reaction experience and mitigation: Delphi analysis of the ALLOW study. Neurodegener Dis Manag. 2017;7:39-47.

12. PLEGRIDY (pegylated interferon beta-1a) [prescribing information]. Cambridge, MA: Biogen; 2021.

13. Naismith RT, Hendin B, Wray S, et al. Patients transitioning from non-pegylated to pegylated interferon beta-1a have a low risk of new flu-like symptoms: ALLOW phase $3 \mathrm{~b}$ trial results. Mult Scler J Exp Transl Clin. 2019;5:2055217318822148. 